\title{
Lutzomyia longipalpis Antimicrobial Peptides: Differential Expression during Development and Potential Involvement in Vector Interaction with Microbiota and Leishmania
}

\author{
Erich Loza Telleria ${ }^{1,2}{ }^{\oplus}$, Bruno Tinoco-Nunes ${ }^{1}$, Tereza Leštinová ${ }^{2}$, Lívia Monteiro de Avellar ${ }^{1}$, \\ Antonio Jorge Tempone ${ }^{1} \mathbb{D}$, André Nóbrega Pitaluga ${ }^{1}$, Petr Volf ${ }^{2} \mathbb{D}$ and Yara Maria Traub-Csekö ${ }^{1, *}$ \\ 1 Laboratório de Biologia Molecular de Parasitas e Vetores, Instituto Oswaldo Cruz, Fiocruz, Av. Brasil 4365, \\ Rio de Janeiro 21040-360, Brazil; erich.telleria@gmail.com (E.L.T.); croookes@gmail.com (B.T.-N.); \\ liviaavellar895@gmail.com (L.M.d.A.); tempone@ioc.fiocruz.br (A.J.T.); pitaluga@ioc.fiocruz.br (A.N.P.) \\ 2 Department of Parasitology, Faculty of Science, Charles University, Viničná 7, 12844 Prague, Czech Republic; \\ Terka.Kratochvilova@seznam.cz (T.L.); volf@cesnet.cz (P.V.) \\ * Correspondence: ytraub@ioc.fiocruz.br
}

check for updates

Citation: Telleria, E.L.; Tinoco-

Nunes, B.; Leštinová, T.; de Avellar, L.M.; Tempone, A.J.; Pitaluga, A.N.; Volf, P.; Traub-Csekö, Y.M. Lutzomyia longipalpis Antimicrobial Peptides: Differential Expression during Development and Potential Involvement in Vector Interaction with Microbiota and Leishmania. Microorganisms 2021, 9, 1271. https://doi.org/10.3390/ microorganisms 9061271

Academic Editor: Helena Castro

Received: 28 December 2020

Accepted: 15 February 2021

Published: 11 June 2021

Publisher's Note: MDPI stays neutral with regard to jurisdictional claims in published maps and institutional affiliations.

Copyright: () 2021 by the authors. Licensee MDPI, Basel, Switzerland. This article is an open access article distributed under the terms and conditions of the Creative Commons Attribution (CC BY) license (https:// creativecommons.org/licenses/by/ $4.0 /)$.

\begin{abstract}
Antimicrobial peptides (AMPs) are produced to control bacteria, fungi, protozoa, and other infectious agents. Sand fly larvae develop and feed on a microbe-rich substrate, and the hematophagous females are exposed to additional pathogens. We focused on understanding the role of the AMPs attacin (Att), cecropin (Cec), and four defensins (Def1, Def2, Def3, and Def4) in Lutzomyia longipalpis, the main vector of visceral leishmaniasis in the Americas. Larvae and adults were collected under different feeding regimens, in addition to females artificially infected by Leishmania infantum. AMPs' gene expression was assessed by qPCR, and gene function of Att and Def2 was investigated by gene silencing. The gene knockdown effect on bacteria and parasite abundance was evaluated by qPCR, and parasite development was verified by light microscopy. We demonstrate that L. longipalpis larvae and adults trigger AMPs expression during feeding, which corresponds to an abundant presence of bacteria. Att and Def2 expression were significantly increased in Leishmaniainfected females, while Att suppression favored bacteria growth. In conclusion, L. longipalpis AMPs' expression is tuned in response to bacteria and parasites but does not seem to interfere with the Leishmania cycle.
\end{abstract}

Keywords: Lutzomyia longipalpis; antimicrobial peptides; innate immunity; RNAi gene silencing; Leishmania; microbiota

\section{Introduction}

Antimicrobial peptides (AMPs) are typically cationic peptides with an overall positive charge and hydrophobic amino acid residues [1]. They can kill or neutralize Gram-negative and Gram-positive bacteria, fungi, and parasites [2,3]. There are several possible mechanisms through which AMPs may act, including depolarization of the bacterial membrane [4] and the creation of pores that cause loss of cellular contents [5].

In insects, one classical and well-known aspect of immunity is fat body AMPs synthesis and release into hemolymph. This response in Drosophila is coordinated by the Toll and IMD pathways, which are the major immunity regulatory pathways in this insect [6]. Conserved microbial molecular patterns are quickly recognized by pattern recognition receptors which initiate complex intracellular signaling cascades. The innate immune recognition triggers the formation of multi-protein complexes that include kinases and transcription factors, among other regulatory molecules, and culminates in AMP expression [7,8]. Different AMPs can be expressed concomitantly, therefore acting in synergy [9]. Here we focused on three types of AMPs: attacins, cecropins, and defensins.

Attacins form a heterogeneous group of proteins (attacin/sarcotoxin-II family) that vary in size but share common glycine-rich residues. The majority of attacins are active 
against Escherichia coli and other Gram-negative bacteria [10]. Attacins have also antiparasitic activity. The tsetse fly Glossina morsitans attacin-A1 acts against Trypanosoma brucei bloodstream and procyclic forms in in vitro assays, reducing parasite survival in the fly midgut when added to the infective blood meal [11]. Cecropins are peptides with 3139 residues with amidated C-termini and a linear $\alpha$-helical structure without cysteine residues [12]. They display broad-spectrum activity against Gram-negative and Grampositive bacteria [13,14], and fungi [15]. Synthetic cecropin or cecropin-like peptides cause a reduction of Plasmodium ookinetes development in in vitro assays [16,17]. It also reduces oocysts in Anopheles albimanus when the peptide is added to infective blood meal [16] or injected in the thorax of previously infected Anopheles gambiae [18]. Insect defensins are small cationic peptides of 34-51 residues with six conserved cysteines, and three intramolecular disulfide bonds [19]. Defensins acts on a diverse range of bacteria, usually more efficiently toward Gram-positive than Gram-negative organisms [20]. They also affect fungi and eukaryotic cells. They are detected in the insect hemolymph soon after infection or injury [21] and can act instantaneously to kill bacteria [22]. Aeschna cyanea (dragonfly) and Phormia terranovae (flesh fly) defensins can profoundly affect Plasmodium gallinaceum parasites, reducing oocysts number in Aedes aegypti and altering sporozoite morphology with consequent loss of motility [23].

Sand flies (Diptera: Psychodidae, Phlebotominae) are vectors of viruses, bacteria, and protozoans that cause diseases of public health importance [24]. Several species belonging to the Lutzomyia and Phlebotomus genera are proven vectors of human leishmaniasis and more than 1 billion people are at risk of acquiring the disease [25]. Female sand flies ingest Leishmania parasites together with blood when feeding on an infected host. Inside the sand fly gut, Leishmania parasites undergo a sequence of multiplication and differentiation steps that culminate with the development of an infective form which can be transmitted to another host through the sand fly bite $[26,27]$. During this process, the vector immunity is regulated to control microbial challenges [28].

Early reports on sand fly AMPs identified a cecropin-like peptide in L. longipalpis [29], and a defensin peptide in Phlebotomus duboscqi [30] hemolymph after being injected with bacteria. Later, a defensin gene was identified in L. longipalpis [31] and the expression of this gene was shown to be upregulated in females fed with Gram-negative and Gram-positive bacteria [32]. Although earlier studies identified AMPs in adult sand flies, three other AMPs, an attacin (Att), a cecropin (Cec), and a second defensin (Def2), were shown to be modulated in L. longipalpis LL5 embryonic cells under microbial challenges, possibly regulated by Toll and IMD pathways concomitantly [33]. Having this set of AMPs identified in L. longipalpis, we hypothesized first that these AMPs were expressed either to balance or control the presence of commensal or possibly harmful microbes (in larvae or adult sand flies) and Leishmania (in female sand flies); and, second, that the suppression of AMPs by RNAi-mediated gene silencing could influence the microbiota and Leishmania development in the female. In the present work, we addressed these hypotheses by selecting different feeding regimens of larvae and adult sand flies and evaluated AMP gene expression levels. We also selected two AMPs (Att and Def2) for silencing in female sand flies followed by Leishmania artificial infection, and assessed the parasite and microbiota abundance using qPCR, and parasite development using light microscopy techniques.

\section{Materials and Methods}

\subsection{AMPs Sequences}

L. longipalpis attacin (Att) (GenBank KP030755), cecropin (Cec) (GenBank KP030754), defensin 1 (Def1) (GenBank EF491251), and defensin 2 (Def2) (GenBank KP030758) were identified in previous studies [31,33]. Defensin 3 (Def3) (MW269862) and defensin 4 (Def4) (MW269863) were identified using hidden Markov models (HMMER) of insect defensins as a query for a blastp analysis on an unassembled genomic sequence database of L. longipalpis (GenBank PRJNA20279). L. longipalpis defensin amino acid sequences were analyzed using the InterPro Classification of Protein Families 81.0 tool [34]. Similarities of L. longipalpis 
AMP amino acid sequences with other insects were assessed by ClustalW multiple alignment tool [35], followed by phylogenetic analysis using MEGA6 software [36], with the maximum likelihood method and the Le_Gascuel_2008 model [37]. Gamma distribution was used to model evolutionary rate differences among sites and bootstrapping with 100 replicates.

\subsection{Lutzomyia Longipalpis}

L. longipalpis larvae and adult stages were obtained from a previously established colony originally collected in Jacobina, BA, Brazil, and kept under standard insectary conditions at temperatures between 24 and $28{ }^{\circ} \mathrm{C}$ and $70-80 \%$ relative humidity [38]. For colony maintenance, adult insects were fed on $50-70 \%$ sucrose ad libitum, and females were blood-fed on anesthetized hamsters or mice once per week. For experimental procedures, sand flies were collected as follows. Larvae at 3rd (L3), 4th (L4), or pre-pupae instars were collected from rearing pots and cleaned with thin dry brushes. The first and second larval stages were not collected due to their diminutive size. Emerged male and female sand flies ( 1 to 3 days old) were released into rearing cages and non-fed insects were collected immediately prior to offering sugar-meal. Sugar-fed insects were collected at 24 and $48 \mathrm{~h}$ post-feeding (PF) ad libitum on sugar-meal containing blue aniline to positively identify fed insects. Female sand flies ( 3 to 6 days old) were artificially fed through chick skin membrane on rabbit blood seeded with Leishmania infantum $\left(10^{6}\right.$ parasites $/ \mathrm{mL}$ of blood), while control groups were fed on blood without parasites under the same conditions. Fully engorged females were separated and collected at different times PF $(24,48,72$, and $96 \mathrm{~h})$ for RNA extraction and microscopy analysis (192 h). All samples were collected in pools of 10 larvae or adult sand flies.

\subsection{RNA Extraction and cDNA Synthesis}

Larvae or adult sand flies pools were collected at different stages or timepoints PF (described above) for total RNA extraction using TRIzol ${ }^{\mathrm{TM}}$ Reagent (Invitrogen, Carlsbad, CA, USA) according to the manufacturer's instructions. Extracted RNA was incubated with RNase-free DNase I (Thermo Scientific, Carlsbad, CA, USA) at $1 \mathrm{U} / \mu \mathrm{g}$ of total RNA for removing possible traces of genomic DNA. Up to $1 \mu \mathrm{g}$ of total RNA was used in reverse transcriptase reactions to produce cDNA using SuperScript III Reverse Transcriptase (Invitrogen). Protocols were followed according to the manufacturers' instructions.

\subsection{RNAi-Mediated Gene Silencing}

Gene-specific primers (dsAtt-F, dsAtt-R, dsDef2-F, and dsDef2-R) coupled to a T7 promoter sequence (Table S1) were designed to amplify templates from sand fly cDNA by PCR. dsLacZ-F and dsLacZ-R primers were used to amplify the template from $p$ GEM-T Easy plasmid (Promega) as control dsRNA. Touchdown PCR was used as follows: $95^{\circ} \mathrm{C}$ for $3 \mathrm{~min}$; 16 cycles of $95^{\circ} \mathrm{C}$ for $45 \mathrm{~s}, 68$ to $50{ }^{\circ} \mathrm{C}$ (progressively decreasing $1{ }^{\circ} \mathrm{C}$ per cycle) for $45 \mathrm{~s}$, and $72{ }^{\circ} \mathrm{C}$ for $45 \mathrm{~s} ; 26$ cycles of $95{ }^{\circ} \mathrm{C}$ for $45 \mathrm{~s}, 50{ }^{\circ} \mathrm{C}$ for $45 \mathrm{~s}$, and $72{ }^{\circ} \mathrm{C}$ for $45 \mathrm{~s} ; 72{ }^{\circ} \mathrm{C}$ for $3 \mathrm{~min}$. These templates were purified by Wizard SV Gel and PCR cleanup system (Promega) and used in dsRNA synthesis reaction by MEGAscript RNAi kit (Invitrogen) following the manufacturer's instructions. The produced dsRNA was lyophilized and resuspended in ultrapure $\mathrm{H}_{2} \mathrm{O}$ to $4.5 \mu \mathrm{g} / \mu \mathrm{L}$ final concentration. Sand flies were microinjected intrathoracically with $32.2 \mathrm{~nL}$ of dsRNA using Nanoject II microinjector (Drummond) [39].

\subsection{Gene Expression Analysis by $q P C R$}

The gene expression was assessed by qPCR using cDNA templates, gene specificprimers (Table S1), and SYBR Green PCR Master Mix in a 7500 Real-Time PCR System (Applied Biosystems) following the manufacturer's standard cycling conditions. The gene expression was calculated relative to a ribosomal protein (RP49) reference gene 
and expressed in fold change values in comparison to a control group [33] following the $\Delta \Delta \mathrm{C}_{\mathrm{T}}$ method [40].

\subsection{Leishmania Development in Sand Fly Guts}

On day 8 post-infection, a minimum of 20 sand fly guts were examined by light microscopy for parasite load, localization, and development. Guts were dissected in saline solution $(\mathrm{NaCl} 0.9 \%)$ and examined under a $40 \times$ magnification objective lens. Parasite loads were estimated and classified as low (below 100 parasites), medium (between 100 and 1000 parasites), or heavy infection (above 1000 parasites) [41]. The parasite localization throughout the gut (abdominal or thoracic gut, cardia, and colonized stomodeal valve) was recorded [41,42]. In addition, parasite developmental stages were inspected on sand fly gut smears on Giemsa-stained glass slides under a 100 $\times$ magnification objective lens. Images of 100 randomly selected promastigotes were captured, and cell width, length, and flagellum were measured using the microscope scale plugin in ImageJ 1.52a software [43]. Parasites were categorized as elongated nectomonads (body length $\geq 14 \mu \mathrm{m}$ ), procyclic promastigotes (body length $<14 \mu \mathrm{m}$ and flagellar length $\leq$ body length), metacyclic promastigotes (body length $<14 \mu \mathrm{m}$ and flagellar length $\geq 2 \times$ body length), leptomonads (remaining parasites) [42,44]. Samples were collected from a minimum of 3 independent experiments.

\subsection{Statistical Analysis}

The Kruskal-Wallis test with Dunn's correction for multiple comparison was used to calculate significant differences in gene expression levels of larval stages L3 and L4 in comparison to pre-pupal stages, and differences of adult sand flies (males and females) fed on sucrose collected at 24 and $48 \mathrm{~h}$ in comparison to non-fed sand flies.

Ordinary two-way ANOVA with Sidak's correction for multiple comparisons test was used to calculate significant differences in: (a) gene expression levels in Leishmania-infected in comparison to blood fed females, both collected at several time points post-feeding; (b) gene expression levels between Att and Def2 dsRNA injected in comparison to LacZ dsRNA injected females collected at several time points post-injection, and (c) infection estimation and localization and parasite morphology in samples collected from Att and Def2 dsRNA injected in comparison to LacZ dsRNA injected females. The statistical analysis was carried in GraphPad Prism software (version 6.07) (GraphPad Software Inc., San Diego, CA, USA).

\section{Results}

\subsection{AMP Sequences}

Phylogenetic analysis showed that L. longipalpis Att amino acid sequence [33] is closely related to the sequences of the sand flies Nyssomyia neivai (GenBank JAV08575) and P. papatasi (VectorBase PPAI003791-RA), forming a separate group from other insect sequences (Figure S1). Cec [33] forms a group with P. papatasi (VectorBase PPAI003330-RA), separated from the $A$. gambiae sequence (Figure $\mathrm{S} 2$ ).

Def1 and Def2 were previously identified $[31,33]$ and in the present work we described two other defensin sequences Def3 and Def4 that contain the six conserved cysteine residues (Figure S3) characterizing these AMPs (InterPro IPR001542) [34]. The four L. longipalpis defensins contain an arthropod defensin-2 superfamily motif (pfam01097) [34]. Def3 and Def 4 share $70.45 \%$ and $53.93 \%$ of similarity with Def1, respectively, and they both share less than 50\% similarity with Def2 (Table S2). Phylogenetic analysis showed that Def1 and Def3 grouped within a same branch. Def4 forms a sister branch that includes a P. papatasi sequence (VectorBase PPAI004255-RA). Def2 forms a group with the N. neivai defensin 2 sequence (GenBank JAV13023) and is more distantly related to the other L. longipalpis defensins (Figure S4). 


\subsection{AMP Expression in Larval Stages}

Sand fly larvae develop and feed on a microbe-rich substrate which could impact AMP expression. We evaluated the expression levels of attacin, cecropin and four defensin genes in L. longipalpis L3 and L4 instar larvae, in comparison to the pre-pupal (PP) stage that interrupts feeding prior to pupation and defecates the midgut content. There is a significant increase in Att, Def2, and Def4 in L3 stages (Figure 1A,D,F), whereas Cec, Def1, and Def3 do not show a significant difference among these stages (Figure 1B,C,E). Bacteria loads estimated by the $16 \mathrm{~S}$ ribosomal RNA primers showed that L3 and L4 stages harbor more bacteria than the PP stage (Figure 1G).
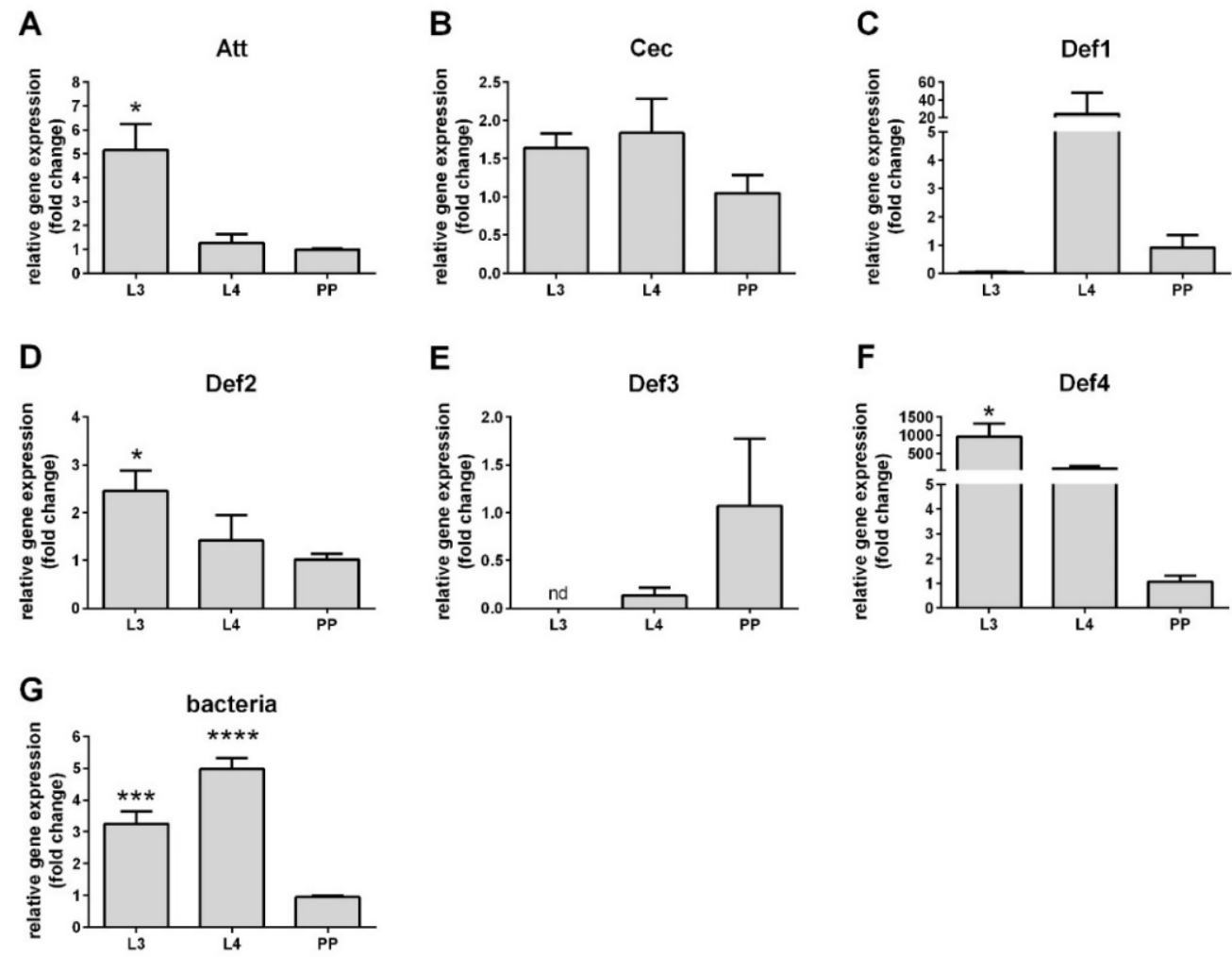

Figure 1. Relative gene expression of antimicrobial peptides (AMPs) in larval stages. (A) attacin; (B) cecropin, (C) defensin 1; (D) defensin 2; (E) defensin 3; (F) defensin 4; (G) bacteria 16S. The y-axis represents relative expression values expressed in foldchange in comparison to the pre-pupae stage. The $x$-axis represents larval stages L3, L4, and pre-pupal (PP). Vertical bars represent the average values of three independent experiments, and error bars represent the standard error. Asterisks indicate significant differences $\left({ }^{*} p<0.05 ;{ }^{* * *} p<0.001 ;{ }^{* * *} p<0.0001\right)$. (nd) not detected.

\subsection{AMP Expression in Sugar-Fed Adult Sand Flies}

After the emergence of imagoes, insects were fed a sucrose rich solution, which can stimulate gut microbiota growth. Upon sugar intake, these insects might also modulate their AMP expression in response to the microbial community growth. We observed that, in males, Att, Cec, Def2, and Def4 are significantly increased at $48 \mathrm{~h}$ PF (Figure 2A,B,D,F). Def1 and Def3 are highly expressed at 24 and $48 \mathrm{~h}$ in comparison to non-fed males (Figure 2C,E). In females, Att and Cec are reduced at $48 \mathrm{~h}$ (Figure 2G,H), whereas Def3 is reduced at 24 and $48 \mathrm{~h}$ PF (Figure 2K). Def1 increased at 24 and $48 \mathrm{~h}$ (Figure 2I), whereas Def2 showed no significant difference when compared to non-fed females (Figure 2J). Bacteria loads in males were reduced at $48 \mathrm{~h}$ (Figure $2 \mathrm{M}$ ) and increased in females after feeding on sucrose at 24 and $48 \mathrm{~h}$ PF (Figure $2 \mathrm{~N}$ ). 


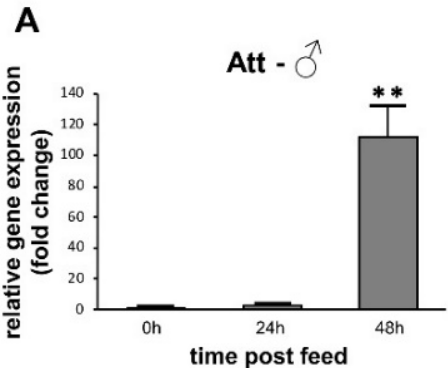

B
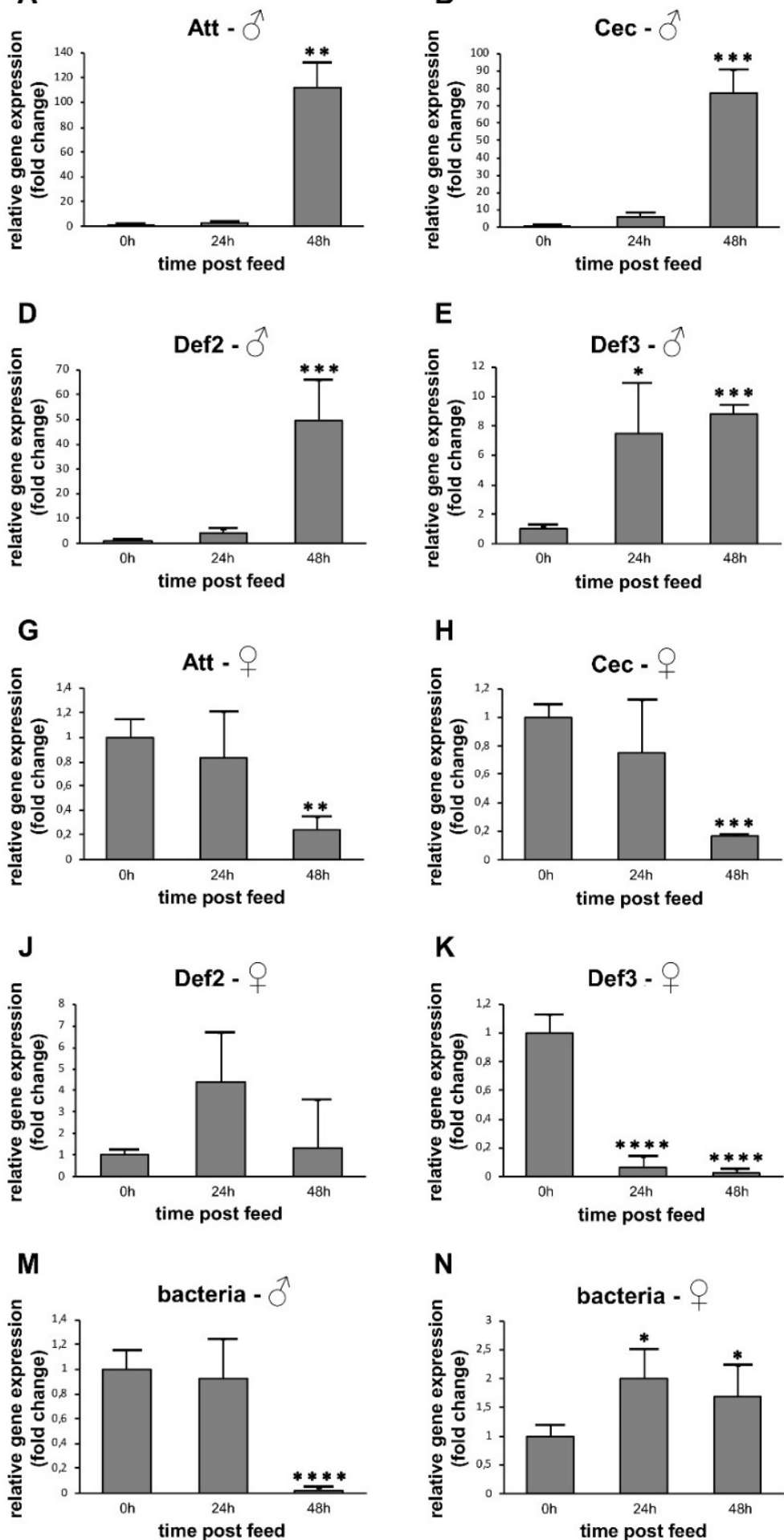

E

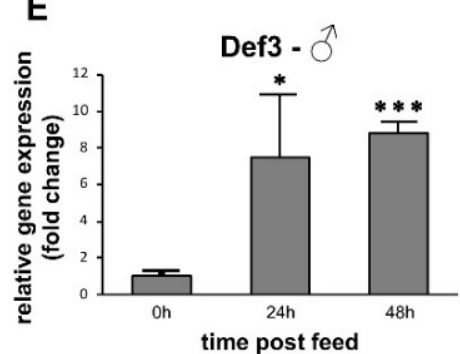

H

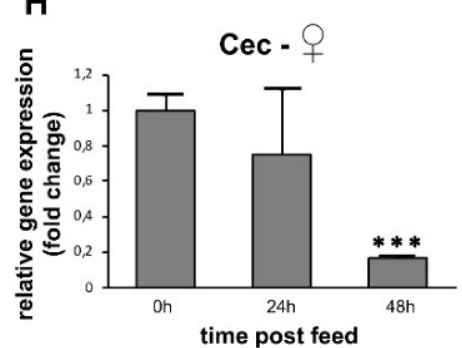

K

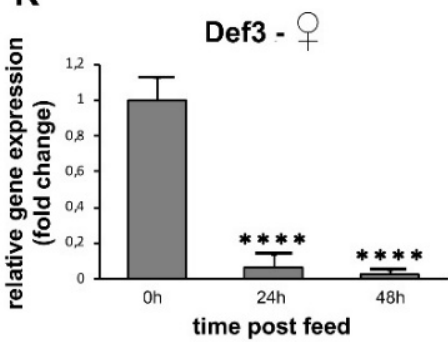

$\mathbf{N}$

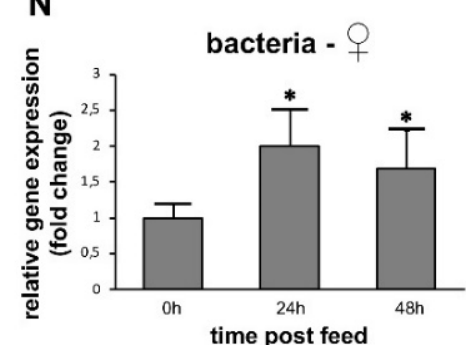

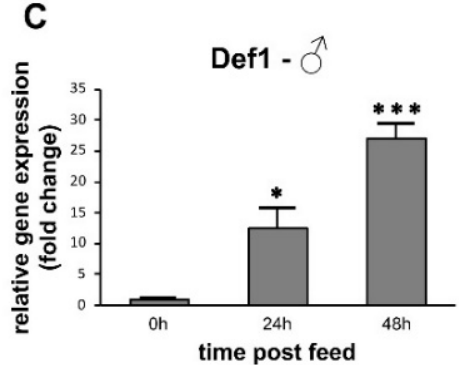

F

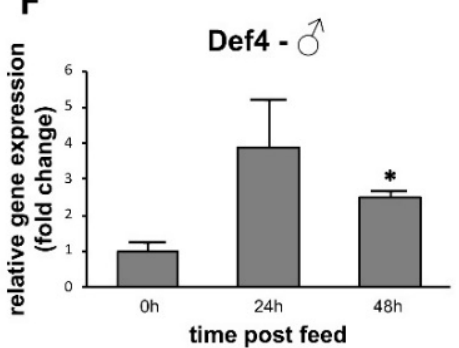

I

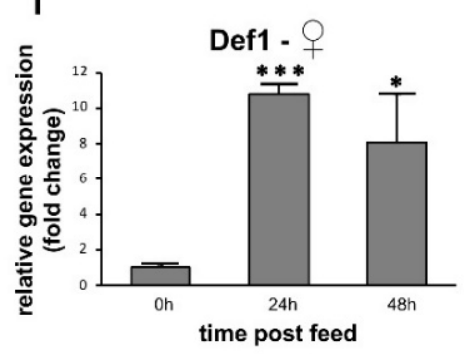

L

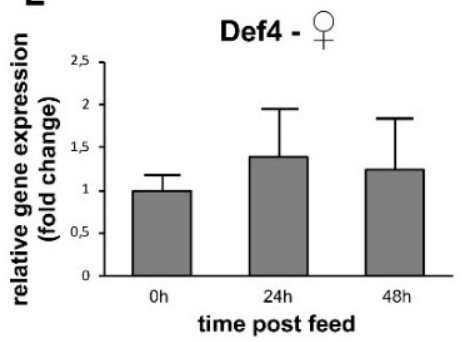

Figure 2. Relative gene expression of AMPs in sugar-fed sand flies. (A-F,M) males; $(\mathbf{G}-\mathbf{L}, \mathbf{N})$ females; $(\mathbf{A}, \mathbf{G})$ attacin; (B,H) cecropin; (C,I) defensin 1; (D,J) defensin 2; (E,K) defensin 3; (F,L) defensin 4; (M,N) bacteria 16S. The $y$-axis represents relative expression values expressed in comparison to non-fed males or non-fed females. The $x$-axis represents the feeding stage: non-fed $(0 \mathrm{~h})$ or sugar-fed collected at 24 and $48 \mathrm{~h}$ post-feeding $(\mathrm{PF})$. Vertical bars represent the average values of three independent experiments, and error bars represent the standard error. Asterisks indicate significant differences $\left({ }^{*} p<0.05 ;{ }^{* *} p<0.01 ;{ }^{* * *} p<0.001 ;{ }^{* * *} p<0.0001\right)$. 


\subsection{AMP Expression in Leishmania-Infected Sand Flies}

Addressing the potential modulation of L. longipalpis AMPs in the presence of Leishmania, we investigated the AMP expression of female L. longipalpis artificially fed a parasiteseeded blood-meal in comparison to a control group fed blood. Att and Def2 expressions were significantly increased at $72 \mathrm{~h}$ (Figure 3A,D) and Cec at 48 and $72 \mathrm{~h}$ (Figure 3B), whereas Def1, Def3, and Def4 showed no significant changes (Figure 3C,E,F). We also evaluated the Leishmania and bacteria content in the infected insects. We observed a parasite load reduction at $72 \mathrm{~h}$ and an increase in bacteria at $48 \mathrm{~h}$ (Figure 3G,H).

A

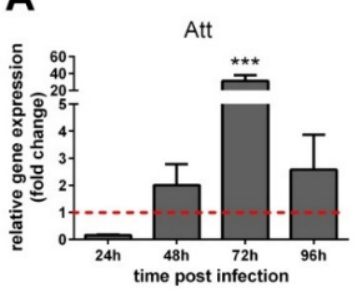

D

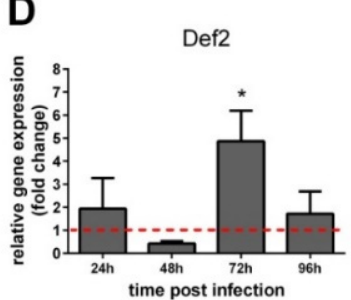

G

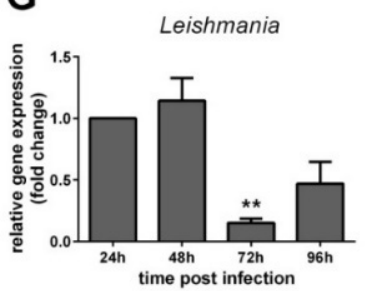

B

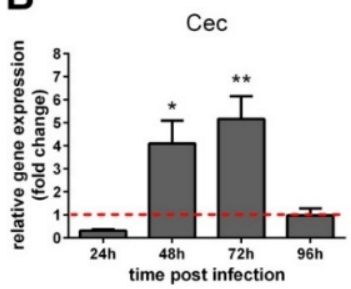

$\mathrm{E}$

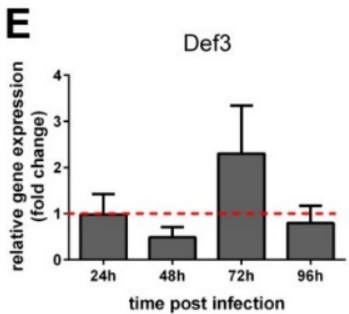

H

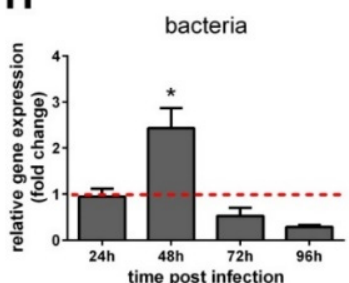

C Def1

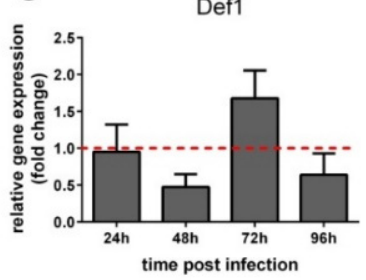

$\mathbf{F} \quad$ Dei4

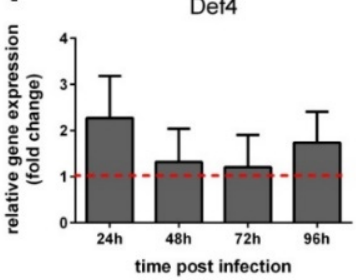

Figure 3. Relative gene expression of AMPs in blood-fed females infected by Leishmania. (A) Att; (B) Cec; (C) Def1; (D) Def2; (E) Def3; (F) Def4; (G) Leishmania actin; (H) bacteria 16S ribosomal RNA. The $y$-axis represents relative gene expression as fold change values, in comparison to the control group of blood-fed females (dotted line) collected at the corresponding time points $(\mathbf{A}-\mathbf{F}, \mathbf{H})$; Leishmania detection was expressed in comparison to $24 \mathrm{~h}(\mathbf{G})$. The $x$-axis represents females collected at first to fourth day PF. Vertical bars represent the average values of three independent experiments, and error bars represent the standard error. Asterisks indicate significant differences ${ }^{*} p<0.05$; $\left.{ }^{* *} p<0.01 ;{ }^{* * *} p<0.001\right)$.

\subsection{AMP Gene Silencing Followed by Leishmania Infection}

Considering the Att and Def2 significant expression increases in Leishmania infected females, we hypothesized that RNAi-mediated gene silencing of these genes could interfere with the parasite growth in artificially infected sand flies. We first tested if Att- and Def2dsRNAs would silence their corresponding genes using recently emerged flies kept under colony conditions fed sucrose solution. Both genes were successfully silenced at 24 and $48 \mathrm{~h}$ post-dsRNA injection when compared to the control group injected with LacZ dsRNA (Figure S5A,B). For testing Att and Def2 gene silencing effect in Leishmania infection, insects were injected with dsRNA and artificially fed an infective blood meal on the following day. Att-dsRNA significantly reduced Att gene expression from 24 to $72 \mathrm{~h}$ post-infection (Figure S5C), and Def2-dsRNA reduced Def2 gene expression from 48 to $72 \mathrm{~h}$ post-infection (Figure S5D). 
The parasite load in Att-silenced group remained similar to the control group from 24 to $72 \mathrm{~h} \mathrm{PF}$ (Figure 4A). We also investigated the effect of Att silencing in the insect microbiota. There was a significant increase in the bacteria levels at $72 \mathrm{~h}$ post-infection (Figure 4B). In Def2-silenced sand flies, we observed a slight but non-significant variation of Leishmania detection on first- and third-days post-infection (Figure 4C) and non-significant bacterial increase on the first day post-infection (Figure 4D).

A

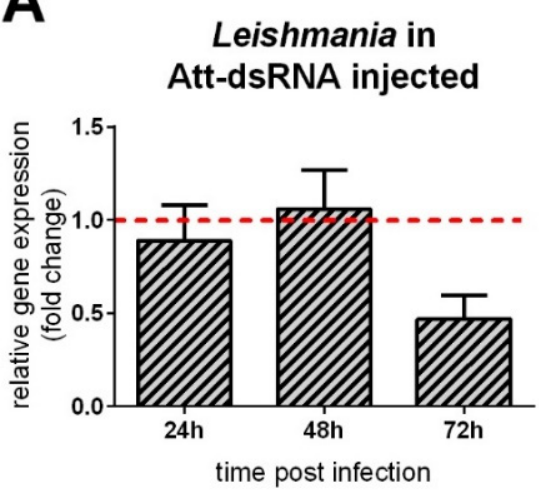

C

Leishmania in Def2-dsRNA injected

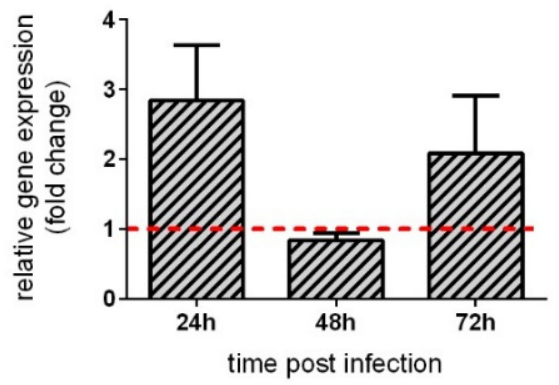

B

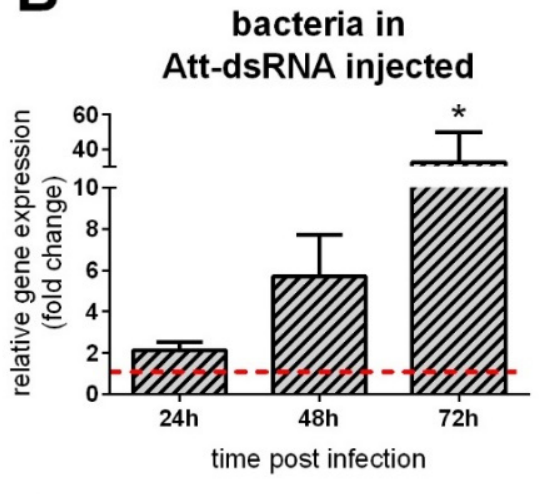

D
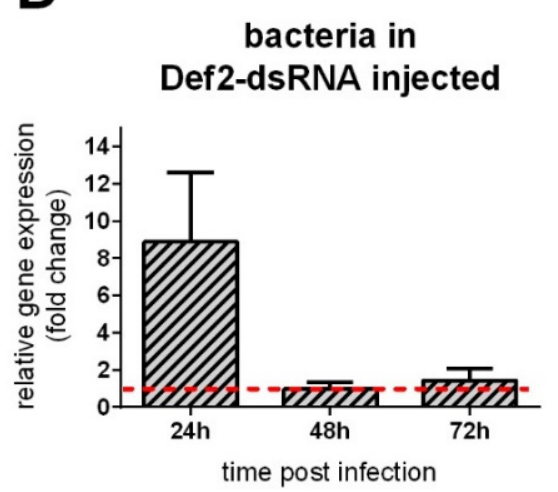

Figure 4. Relative gene expression of AMPs in dsRNA injected females Figure 2. dsRNA-injected; $(A, C)$ Leishmania actin; (B,D) bacteria 16S ribosomal RNA. The $y$-axis represents relative gene expression as fold change values of Att or Def2-dsRNA injected insects in comparison to the LacZ-dsRNA injected control group. The $x$-axis represents females collected at first to third days post-infectious feeding. Vertical bars represent the average values of three independent experiments, and error bars represent the standard error. Asterisks indicate significant differences $\left({ }^{*} p<0.05\right)$.

\subsection{Leishmania Late Infection in RNAi-Silenced Sand Flies}

To explore Att and Def2 silencing effect on the parasite development and colonization progress in the insect gut, we estimated the infection load, assessed the parasite localization and morphology in L. longipalpis gut at $192 \mathrm{~h}$ post-infection using light microscopy. No significant differences were detected in infection estimation levels in Attor Def2-dsRNA-injected sand flies in comparison to the LacZ-dsRNA-injected control group (Figure 5A). There was a non-significant increase in thoracic gut localization in Def2-dsRNA-injected groups (Figure 5B). We also evaluated the parasite morphology in Giemsa-stained gut smears, and no significant difference was observed between the dsRNA-injected groups (Figure 5C). 
A

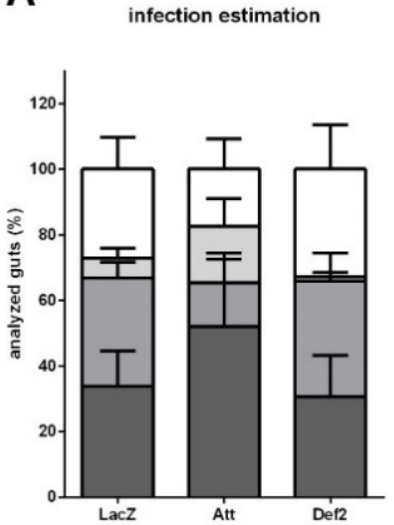

B

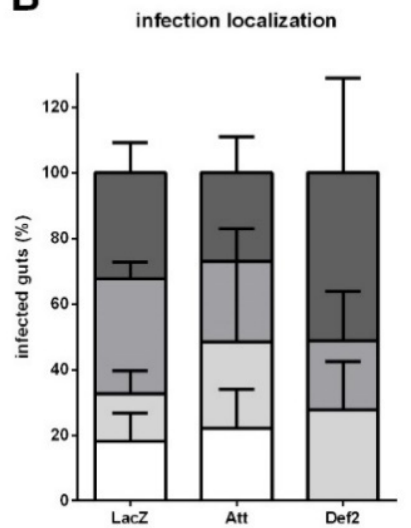

C

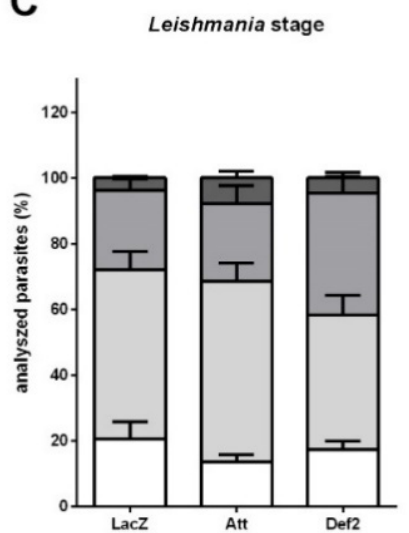

Figure 5. Infection intensity and development at late infection in dsRNA-injected sand flies. (A) The $y$-axis represents the percentage of all individually inspected insects (minimum of 20 sand flies in each dsRNA injected group). Bar colors indicate infection intensity: non-infected (white); with low (light grey); medium (mid grey); and heavy (dark grey) infections. (B) The $y$-axis represents the percentage in infected insects to measure the infection progress in the gut. Bar colors indicate sand fly gut localization: parasites reached the stomodeal valve (dark grey); cardia (mid grey); thoracic gut (light grey); or stayed in abdominal gut (white). (C) The $y$-axis represents the percentage of analyzed parasites to measure parasite development in the sand fly gut. Bar colors indicate parasite developmental stage: metacyclic promastigote (dark grey); leptomonad (mid grey); elongated nectomonad (light grey); procyclic promastigote (white). The $x$-axis represents dsRNA injected groups. Vertical bars represent the average values of three independent experiments, and error bars represent the standard error. No significant differences were found.

\section{Discussion}

We have previously identified and characterized an attacin (Att), a cecropin (Cec), and two defensin genes (Def1 and Def2) [31-33] in L. longipalpis. In the present study, we investigated the expression of these AMP genes, in addition to two other defensin genes (Def3 and Def4).

Phylogenetic studies show that different sand flies' Att sequences are closely related to each other and are less similar to other vectors, such as G. morsitans and Aedes albopictus. Similarly, phlebotomine Cec sequences are closely related to each other and grouped separately from other insects. The close similarities of Att or Cec between sand fly species can be explained by the natural evolution resulting from a common ancestor. Nevertheless, Def3 is closely related to Def1, whereas Def2 shares fewer similarities with the other L. longipalpis defensins. An additional evolutionary pressure appears to occur in these genes. For instance, defensins from different organisms were classified into two superfamilies as a result of independent evolutionary origins, with structural and functional similarities. A larger group consists of cis-defensins found in plants, fungi, and invertebrates, which includes the L. longipalpis defensins. The smaller group consists of trans-defensins from vertebrate and invertebrate defensins that contain eight conserved cysteines. Each of these superfamilies went through subsequent divergent evolution [45].

In nature, L. longipalpis larvae develop in soil sites that generally contain organic matter derived from decaying plants and animal droppings [46,47]. These environments often harbor a diversity of microorganisms [48-50] that can be ingested when larvae feed on the available substrates, further contributing to the diversity of the sand fly gut microbiome [28]. In P. duboscqi and Lutzomyia evansi, microbial community varies depending on developmental stage [51-53], indicating that breeding sites and feeding habits together influence microbiota diversity and abundance.

Our present results regarding L. longipalpis larvae AMP gene expression showed Att, Def2, and Def4 up modulation in L3 but not in L4 larval stages in comparison to the nonfeeding pre-pupal (PP) stage. This finding may be related to highly active and voracious 
feeding habits of sand fly L3 stage [54,55]. Nevertheless, bacterial loads in both L3 and L4 stages are higher, suggesting bacterial abundance is not the only factor influencing AMPs regulation. It is possible that gut bacterial diversity changed through these developmental stages and the insect adjusted expression of a specific set of AMPs to control the gut microbial community. It is interesting to note that Bacillus subtilis or Pantoea agglomerans artificial feeding caused a reduction in Att expression in L. longipalpis L3 larvae at $12 \mathrm{~h} \mathrm{PF}$, whereas Def1 was increased at $24 \mathrm{~h}$ after feeding on P. agglomerans [54]. These findings indicate that the larvae immune system may be tuned according to a diverse microbiome and distinguish bacterial strains to support larval development.

The gut microbial load control allows a reduced set of bacteria, such as Ochrobactrum sp., to be carried from larval to pupae and adult sand flies [51,56,57]. This finding may reflect the adaptative advantage in hosting commensal or symbiotic bacteria that will protect the insect host from pathogenic infections while provide essential nutrients [58]. Therefore, it is plausible to consider that newly emerged L. longipalpis successfully balance the microbial exposure throughout metamorphosis. As probing surfaces resume, sand flies are exposed to new sources of microbes [51]. Moreover, the newly ingested nutrients may be beneficial to the remaining or resident bacteria. For instance, both male and female sand flies feed on plant-derived food sources such as nectar, honeydew, or phloem sap in nature [59-62], but under laboratory conditions, a sucrose-rich solution is used as a substituent of the carbohydrate-rich source from plants. Therefore, during sucrose feeding, a small amount of the ingested sucrose first passes through the stomodeal valve, and then a larger amount is stored in the crop [63]. As a result, the carbohydrate nutrient is readily available in the gut and to the resident bacteria.

We investigated the AMP expression in adult sand flies (males and females) after emergence (non-fed) and after sucrose feeding. In L. longipalpis males, AMP expression was increased either on the first- or second-day post-sucrose feeding which reflects the need to balance the microbial community in the gut. Because they feed exclusively on sucrose-rich food, they may have adapted to a stronger antibacterial immune response to control the growth of carbohydrate-related bacteria in their gut. Alternatively, males could be expressing higher levels of AMPs to transfer them to females during mating, as seen in Drosophila males that express andropin [64] in accessory glands or ejaculatory ducts, and transfer it within the seminal fluid [65]. For example, drosomycin is detected in Drosophila ejaculatory structures and is likely to be present in the ejaculate [66]. In addition, in L. longipalpis sugar-fed females, our results show that the initial response occurs through Def1 expression possibly due to the consequent bacterial growth. Indeed, L. longipalpis females fed a sucrose diet showed higher bacterial diversity when compared to blood-fed sand flies [67]. The reduction of Att, Cec, and Def3 reveals a balanced AMP expression and it is plausible to assume that they are adjusted according to the changes in bacteria diversity.

In previous work, we showed that Def1 expression in sand fly females fed different bacteria added to the sucrose meal varied significantly depending on which bacteria were ingested when compared to the control group fed on sucrose only. Def1 was upregulated by E. coli, Ochrobactrum sp., Serratia marcescens, and M. luteus, and downregulated by Pantoea agglomerans feeding challenges [32], again indicating that the sand fly immune response distinguishes among different pathogens.

No previous data has been published on Att, Cec, and Def2 expression in L. longipalpis female under different feeding conditions or under different bacterial challenges. Nevertheless, in LL5 embryonic cells, Att expression increased after Staphylococcus aureus, Serratia marcescens, and the yeast Saccharomyces cerevisiae exposure; Cec increased after E. coli; and Def2 increased after E. coli and S. aureus ingestion [33]. This adjusted sand fly immune response against a variety of bacteria species may be connected to transcription regulators, as seen in Drosophila, where regulators can increase or decrease AMPs' expression [68] with consequent impact on commensal and pathogenic bacteria [69]. 
L. longipalpis is the natural vector of L. infantum in the Americas [70], and we were interested to investigate the sand fly AMP expression during natural parasite-vector interaction. Our results show that Att, Cec, and Def2 are all upregulated on the third day after L. infantum infection when compared to the blood-fed control group. This time point corresponds to blood meal digestion end when the insect peritrophic matrix is degraded [71], and parasites begin to colonize the gut [72]. Our results show that at this same time point, loads of Leishmania are reduced. This finding can be directly related to the increase of AMP levels and/or defecation of blood meal remains [26]. In the present study, we did not address the proportions of each parasite form on the third day post-infection, but previous studies show that at this timepoint nectomonad and leptomonad forms are the most abundant forms [72,73]. Furthermore, the presence of Leishmania infection is associated with a reduction in bacterial diversity following the infection progression $[28,67,74-76]$. As infection continues, for example, on the sixth day when nectomonad forms are still the most abundant forms and metacyclic forms are present [72], we previously showed that Def1 was downregulated in L. longipalpis infected by L. mexicana [32]. The only study that tested a sand fly AMP activity against a set of microbes showed that a P. duboscqi recombinant defensin is active against $L$. major promastigotes and some fungi [30]. Therefore, the sand fly immune response in late-stage Leishmania development may differ according to the reduced diversity of gut microbiota $[67,75]$.

Although it is not yet known if sand fly immune response is driven specifically toward the parasite or the microbial community, we hypothesized that the suppression of these AMPs could benefit the growth of the parasite, bacterial community, or both. To address this point, we suppressed the function of AMPs by RNAi-mediated gene silencing, for which we selected the two significantly upregulated AMPs during L. infantum infection, Att and Def2.

We investigated the parasite load in AMP-silenced insects during three consecutive days after infection by qPCR to assess parasite and bacterial abundance in comparison to the LacZ-dsRNA-injected control group. L. longipalpis Att gene silencing resulted in a slight decrease of L. infantum and a significant increase of bacteria loads on the third day post-infection. These results indicate that the suppression of Att has a more evident effect on bacteria, and the reduction of the parasite may happen as a consequence of the gut microbiome increase. Leishmania detection seems to increase after Def2 is silenced, but the difference is not statistically significant.

We also hypothesized that AMP expression changes, observed in initial days postgene silencing, could impact parasite development in late phase infection. To address this aspect, we investigated the parasite loads and localization in dissected guts on the eighth day post-infection, a time when Leishmania can be already detected in the stomodeal valve $[72,73]$. Dissected guts were individually inspected to estimate the parasite load and gut localization. Samples from Att and Def2-dsRNA injected flies were compared to the LacZ-dsRNA injected group. Our results, showed no significant differences in the parasite loads.

Although overall parasite loads could represent the ability of the parasites to survive and multiply, the localization of the parasites could yield more detailed information on the ability of the parasite to migrate and complete the cycle in the vector. The dsRNAinjected groups comparison showed no significant differences in parasite localization, but the majority of Def2-silenced insects showed parasites in the thoracic part of the insect gut. It is possible to presume that Def2 suppression resulted in conditions that favored parasites to colonize the anterior segment of the sand fly gut.

It appears that Att silencing creates a less favorable environment in the early phase of infection, possibly due to competition with bacteria, but in the late phase of infection, the parasites were able to colonize the gut similarly to the case of the control group. In addition, Def2 silencing apparently creates a more favorable environment in the early phase of infection, affecting the late phase when parasites are more present in gut anterior segments. These signs of parasite localization in the sand fly gut are tightly associated with 
the Leishmania cycle. Therefore, parasite morphological changes could yield additional information on the infection progress. In our experimental settings, the proportion of metacyclic promastigotes did not alter after Att or Def2 silencing.

AMPs are commonly expressed in synergy to achieve efficient microbe control, and the suppression of Att or Def2 may cause minor changes in abundance or localization of L. infantum in L. longipalpis gut, but parasites adapted to the changes in the sand fly immune response. How Leishmania parasites evade the sand fly immune response remains an intriguing aspect that deserves further investigation.

Supplementary Materials: The following are available online at https:/ /www.mdpi.com/article /10.3390/microorganisms9061271/s1, Figure S1: Attacin phylogenetic tree, Figure S2: Cecropin phylogenetic tree, Figure S3: L. longipalpis defensins alignment, Figure S4: Defensin phylogenetic tree, Figure S5: Gene silencing in sucrose-fed and infected females, Table S1: oligonucleotides used in this study, Table S2: L. longipalpis defensins similarity.

Author Contributions: Conceptualization, E.L.T., A.N.P. and Y.M.T.-C.; methodology, E.L.T., T.L. and A.N.P.; validation, E.L.T.; formal analysis, E.L.T., B.T.-N. and A.N.P.; investigation, E.L.T., B.T.-N., T.L., L.M.d.A., A.J.T. and A.N.P.; resources, Y.M.T.-C. and P.V.; data curation, E.L.T., B.T.-N. and A.N.P.; writing—original draft preparation, E.L.T.; writing—review and editing, E.L.T., A.N.P. and Y.M.T.-C.; visualization, E.L.T.; supervision, E.L.T., A.N.P., P.V. and Y.M.T.-C.; project administration, E.L.T., A.N.P., P.V. and Y.M.T.-C.; funding acquisition, Y.M.T.-C., E.L.T. and P.V. All authors have read and agreed to the published version of the manuscript.

Funding: This research was funded by IOC-Fiocruz (PAEF Program), INCT-EM (Institutos Nacionais em Ciencia e Tecnologia-Entomologia Molecular), research grant number CNPq/Proc. 465678/2014-9 and Projeto Inova-Fiocruz. E.L.T. and P.V. were supported by the International Mobility of Researchers at Charles University (CZ.02.2.69/0.0/0.0/16_027/0008495) and by ERD Funds, project CePaViP (16_019/0000759). T.L. was partially supported by Research Center UNCE (project 204072). This study was financed in part by the Coordination for the Improvement of Higher Education Personnel (Coordenação de Aperfeiçoamento de Pessoal de Nível Superior-CAPES)— Finance Code 001.

Institutional Review Board Statement: All procedures involving animals were performed in accordance with the Brazilian Ethics Committee for Animal Use at FIOCRUZ (CEUA L-016/2018).

Data Availability Statement: The newly identified L. longipalpis defensin genes can be found in GenBank, MW269862 and MW269863.

Conflicts of Interest: The authors declare no conflict of interest.

\section{References}

1. Zhang, L.J.; Gallo, R.L. Antimicrobial peptides. Curr. Biol. 2016, 26, R14-R19. [CrossRef] [PubMed]

2. Hancock, R.E.W.; Scott, M.G. The role of antimicrobial peptides in animal defenses. Proc. Natl. Acad. Sci. USA 2000, 97, 8856-8861. [CrossRef]

3. Zasloff, M. Antimicrobial peptides of multicellular organisms. Nature 2002, 415, 389-395. [CrossRef]

4. Westerhoff, H.V.; Juretic, D.; Hendler, R.W.; Zasloff, M. Magainins and the disruption of membrane-linked free-energy transduction. Proc. Natl. Acad. Sci. USA 1989, 86, 6597-6601. [CrossRef] [PubMed]

5. Yang, L.; Weiss, T.M.; Lehrer, R.I.; Huang, H.W. Crystallization of antimicrobial pores in membranes: Magainin and protegrin. Biophys. J. 2000, 79, 2002-2009. [CrossRef]

6. Bulet, P.; Hetru, C.; Dimarcq, J.L.; Hoffmann, D. Antimicrobial peptides in insects; structure and function. Dev. Comp. Immunol. 1999, 23, 329-344. [CrossRef]

7. De Gregorio, E.; Spellman, P.T.; Tzou, P.; Rubin, G.M.; Lemaitre, B. The Toll and Imd pathways are the major regulators of the immune response in Drosophila. EMBO J. 2002, 21, 2568-2579. [CrossRef]

8. Kounatidis, I.; Ligoxygakis, P. Drosophila as a model system to unravel the layers of innate immunity to infection. Open Biol. 2012, 2, 120075. [CrossRef]

9. Tanji, T.; Hu, X.D.; Weber, A.N.R.; Ip, Y.T. Toll and IMD pathways synergistically activate an innate immune response in Drosophila melanogaster. Mol. Cell. Biol. 2007, 27, 4578-4588. [CrossRef]

10. Hultmark, D.; Engstrom, A.; Andersson, K.; Steiner, H.; Bennich, H.; Boman, H.G. Insect immunity. Attacins, a family of antibacterial proteins from Hyalophora cecropia. EMBO J. 1983, 2, 571-576. [CrossRef] 
11. Hu, Y.; Aksoy, S. An antimicrobial peptide with trypanocidal activity characterized from Glossina morsitans morsitans. Insect Biochem. Mol. Biol. 2005, 35, 105-115. [CrossRef]

12. Brady, D.; Grapputo, A.; Romoli, O.; Sandrelli, F. Insect cecropins, antimicrobial peptides with potential therapeutic applications. Int. J. Mol. Sci. 2019, 20, 5862. [CrossRef]

13. Hultmark, D.; Engström, Å.; Bennich, H.; Kapur, R.; Boman, H.G. Insect Immunity: Isolation and Structure of Cecropin D and Four Minor Antibacterial Components from Cecropia Pupae. Eur. J. Biochem. 1982, 127, 207-217. [CrossRef] [PubMed]

14. Li, Z.Q.; Merrifield, R.B.; Boman, I.A.; Boman, H.G. Effects on electrophoretic mobility and antibacterial spectrum of removal of two residues from synthetic sarcotoxin IA and addition of the same residues to cecropin B. FEBS Lett. 1988, 231, 299-302. [CrossRef]

15. Ekengren, S.; Hultmark, D. Drosophila cecropin as an antifungal agent. Insect Biochem. Mol. Biol. 1999, 29, 965-972. [CrossRef]

16. Carmen Rodriguez, M.D.; Zamudio, F.; Torres, J.A.; Gonzalez-Ceron, L.; Possani, L.D.; Rodriguez, M.H. Effect of a cecropin-like synthetic peptide (Shiva-3) on the sporogonic development of plasmodium berghei. Exp. Parasitol. 1995, 80, 596-604. [CrossRef]

17. Boisbouvier, J.; Prochnicka-Chalufour, A.; Nieto, A.R.; Torres, J.A.; Nanard, N.; Possani, L.D.; Delepierre, M. Structural information on a cecropin-like synthetic peptide, Shiva-3 toxic to the sporogonic development of Plasmodium berghei. Eur. J. Biochem. 1998, 257, 263-273. [CrossRef] [PubMed]

18. Gwadz, R.W.; Kaslow, D.; Lee, J.Y.; Maloy, W.L.; Zasloff, M.; Miller, L.H. Effects of magainins and cecropins on the sporogonic development of malaria parasites in mosquitoes. Infect. Immun. 1989, 57, 2628-2633. [CrossRef]

19. Yi, H.Y.; Chowdhury, M.; Huang, Y.D.; Yu, X.Q. Insect antimicrobial peptides and their applications. Appl. Microbiol. Biotechnol. 2014, 98, 5807-5822. [CrossRef]

20. Amerikova, M.; Pencheva, E.I.; Maslarska, V.; Bozhanov, S.; Tachkov, K. Antimicrobial activity, mechanism of action, and methods for stabilisation of defensins as new therapeutic agents. Biotechnol. Biotechnol. Equip. 2019, 33, 671-682. [CrossRef]

21. Lambert, J.; Keppi, E.; Dimarcq, J.L.; Wicker, C.; Reichhart, J.M.; Dunbar, B.; Lepage, P.; Van Dorsselaer, A.; Hoffmann, J.; Fothergill, J. Insect immunity: Isolation from immune blood of the dipteran Phormia terranovae of two insect antibacterial peptides with sequence homology to rabbit lung macrophage bactericidal peptides. Proc. Natl. Acad. Sci. USA 1989, 86, 262-266. [CrossRef]

22. Cociancich, S.; Goyffon, M.; Bontems, F.; Bulet, P.; Bouet, F.; Menez, A.; Hoffmann, J. Purification and characterization of a scorpion defensin, a $4 \mathrm{kDa}$ antibacterial peptide presenting structural similarities with insect defensins and scorpion toxins. Biochem. Biophys Res. Commun. 1993, 194, 17-22. [CrossRef]

23. Shahabuddin, M.; Fields, I.; Bulet, P.; Hoffmann, J.A.; Miller, L.H. Plasmodium gallinaceum: Differential killing of some mosquito stages of the parasite by insect defensin. Exp. Parasitol. 1998, 89, 103-112. [CrossRef] [PubMed]

24. Maroli, M.; Feliciangeli, M.D.; Bichaud, L.; Charrel, R.N.; Gradoni, L. Phlebotomine sandflies and the spreading of leishmaniases and other diseases of public health concern. Med. Vet. Entomol. 2013, 27, 123-147. [CrossRef] [PubMed]

25. WHO. Leishmaniasis-Health Topics. Available online: https://www.who.int/health-topics/leishmaniasis (accessed on 3 December 2020).

26. Dostalova, A.; Volf, P. Leishmania development in sand flies: Parasite-vector interactions overview. Parasit. Vectors 2012, 5, 276. [CrossRef] [PubMed]

27. Anderson, J.M.; Oliveira, F.; Kamhawi, S.; Mans, B.J.; Reynoso, D.; Seitz, A.E.; Lawyer, P.; Garfield, M.; Pham, M.; Valenzuela, J.G. Comparative salivary gland transcriptomics of sandfly vectors of visceral leishmaniasis. BMC Genom. 2006, 7, 52. [CrossRef]

28. Telleria, E.L.; Martins-Da-Silva, A.; Tempone, A.J.; Traub-Cseko, Y.M. Leishmania, microbiota and sand fly immunity. Parasitology 2018, 145, 1336-1353. [CrossRef]

29. Nimmo, D.D.; Ham, P.J.; Ward, R.D.; Maingon, R. The sandfly Lutzomyia longipalpis shows specific humoral responses to bacterial challenge. Med. Vet. Entomol. 1997, 11, 324-328. [CrossRef]

30. Boulanger, N.; Lowenberger, C.; Volf, P.; Ursic, R.; Sigutova, L.; Sabatier, L.; Svobodova, M.; Beverley, S.M.; Spath, G.; Brun, R.; et al. Characterization of a defensin from the sand fly Phlebotomus duboscqi induced by challenge with bacteria or the protozoan parasite Leishmania major. Infect. Immun. 2004, 72, 7140-7146. [CrossRef]

31. Pitaluga, A.N.; Mason, P.W.; Traub-Cseko, Y.M. Non-specific antiviral response detected in RNA-treated cultured cells of the sandfly, Lutzomyia longipalpis. Dev. Comp. Immunol. 2008, 32, 191-197. [CrossRef] [PubMed]

32. Telleria, E.L.; Sant'Anna, M.R.V.; Alkurbi, M.O.; Pitaluga, A.N.; Dillon, R.J.; Traub-Csekö, Y.M. Bacterial feeding, Leishmania infection and distinct infection routes induce differential defensin expression in Lutzomyia longipalpis. Parasites Vectors 2013, 6, 12. [CrossRef] [PubMed]

33. Tinoco-Nunes, B.; Telleria, E.L.; Da Silva-Neves, M.; Marques, C.; Azevedo-Brito, D.A.; Pitaluga, A.N.; Traub-Csekö, Y.M. The sandfly Lutzomyia longipalpis LL5 embryonic cell line has active Toll and Imd pathways and shows immune responses to bacteria, yeast and Leishmania. Parasites Vectors 2016, 9, 222. [CrossRef]

34. Mcwilliam, H.; Valentin, F.; Goujon, M.; Li, W.; Narayanasamy, M.; Martin, J.; Miyar, T.; Lopez, R. Web services at the European Bioinformatics Institute-2009. Nucleic Acids Res. 2009, 37, W6-W10. [CrossRef]

35. Larkin, M.A.; Blackshields, G.; Brown, N.P.; Chenna, R.; McGettigan, P.A.; McWilliam, H.; Valentin, F.; Wallace, I.M.; Wilm, A.; Lopez, R.; et al. Clustal W and Clustal X version 2.0. Bioinformatics 2007, 23, 2947-2948. [CrossRef]

36. Tamura, K.; Stecher, G.; Peterson, D.; Filipski, A.; Kumar, S. MEGA6: Molecular Evolutionary Genetics Analysis version 6.0. Mol. Biol. Evol. 2013, 30, 2725-2729. [CrossRef] 
37. Le, S.Q.; Gascuel, O. An improved general amino acid replacement matrix. Mol. Biol. Evol. 2008, 25, 1307-1320. [CrossRef]

38. Lawyer, P.; Killick-Kendrick, M.; Rowland, T.; Rowton, E.; Volf, P. Laboratory colonization and mass rearing of phlebotomine sand flies (Diptera, Psychodidae). Parasite 2017, 24, 42. [CrossRef]

39. Sant'Anna, M.R.; Alexander, B.; Bates, P.A.; Dillon, R.J. Gene silencing in phlebotomine sand flies: Xanthine dehydrogenase knock down by dsRNA microinjections. Insect Biochem. Mol. Biol. 2008, 38, 652-660. [CrossRef]

40. Schmittgen, T.D.; Livak, K.J. Analyzing real-time PCR data by the comparative CT method. Nat. Protoc. 2008, 3, 1101-1108. [CrossRef] [PubMed]

41. Myskova, J.; Votypka, J.; Volf, P. Leishmania in Sand Flies: Comparison of Quantitative Polymerase Chain Reaction with Other Techniques to Determine the Intensity of Infection. J. Med. Entomol. 2008, 45, 133-138. [CrossRef] [PubMed]

42. Sadlova, J.; Price, H.P.; Smith, B.A.; Votypka, J.; Volf, P.; Smith, D.F. The stage-regulated HASPB and SHERP proteins are essential for differentiation of the protozoan parasite Leishmania major in its sand fly vector, Phlebotomus papatasi. Cell Microbiol. 2010, 12, 1765-1779. [CrossRef] [PubMed]

43. Rasband, W. ImageJ Website. Available online: https://imagej.nih.gov/ij/ (accessed on 10 August 2019).

44. Walters, L.L.; Chaplin, G.L.; Modi, G.B.; Tesh, R.B. Ultrastructural biology of Leishmania (Viannia) panamensis (=Leishmania braziliensis panamensis) in Lutzomyia gomezi (Diptera: Psychodidae): A natural host-parasite association. Am. J. Trop. Med. Hyg. 1989, 40, 19-39. [CrossRef]

45. Shafee, T.M.A.; Lay, F.T.; Phan, T.K.; Anderson, M.A.; Hulett, M.D. Convergent evolution of defensin sequence, structure and function. Cell Mol. Life Sci. 2017, 74, 663-682. [CrossRef]

46. Casanova, C.; Andrighetti, M.T.; Sampaio, S.M.; Marcoris, M.L.; Colla-Jacques, F.E.; Prado, A.P. Larval breeding sites of Lutzomyia longipalpis (Diptera: Psychodidae) in visceral leishmaniasis endemic urban areas in Southeastern Brazil. PLoS Negl. Trop Dis. 2013, 7, e2443. [CrossRef] [PubMed]

47. Ferro, C.; Pardo, R.; Torres, M.; Morrison, A.C. Larval Microhabitats of Lutzomyia longipalpis (Diptera: Psychodidae) in an Endemic Focus of Visceral Leishmaniasis in Colombia. J. Med. Entomol. 1997, 34, 719-728. [CrossRef]

48. Nannipieri, P.; Ascher, J.; Ceccherini, M.T.; Landi, L.; Pietramellara, G.; Renella, G. Microbial diversity and soil functions. Eur. J. Soil Sci. 2003, 54, 655-670. [CrossRef]

49. Mendes, L.W.; Tsai, S.M.; Navarrete, A.A.; de Hollander, M.; van Veen, J.A.; Kuramae, E.E. Soil-Borne Microbiome: Linking Diversity to Function. Microb. Ecol. 2015, 70, 255-265. [CrossRef] [PubMed]

50. Baldrian, P. Forest microbiome: Diversity, complexity and dynamics. FEMS Microbiol. Rev. 2017, 41, 109-130. [CrossRef] [PubMed]

51. Volf, P.; Kiewegova, A.; Nemec, A. Bacterial colonisation in the gut of Phlebotomus duboseqi (Diptera: Psychodidae): Transtadial passage and the role of female diet. Folia Parasitol. 2002, 49, 73-77. [CrossRef] [PubMed]

52. Guernaoui, S.; Garcia, D.; Gazanion, E.; Ouhdouch, Y.; Boumezzough, A.; Pesson, B.; Fontenille, D.; Sereno, D. Bacterial flora as indicated by PCR-temperature gradient gel electrophoresis (TGGE) of 16S rDNA gene fragments from isolated guts of phlebotomine sand flies (Diptera: Psychodidae). J. Vector Ecol. 2011, 36. [CrossRef]

53. Vivero, R.J.; Jaramillo, N.G.; Cadavid-Restrepo, G.; Soto, S.I.; Herrera, C.X. Structural differences in gut bacteria communities in developmental stages of natural populations of Lutzomyia evansi from Colombia's Caribbean coast. Parasit Vectors 2016, 9, 496. [CrossRef]

54. Heerman, M.; Weng, J.L.; Hurwitz, I.; Durvasula, R.; Ramalho-Ortigao, M. Bacterial Infection and Immune Responses in Lutzomyia longipalpis Sand Fly Larvae Midgut. PLoS Negl. Trop. Dis. 2015, 9, e0003923. [CrossRef]

55. Ximenes, M.D.F.F.D.M.; Maciel, J.C.; Jerônimo, S.M.B. Characteristics of the Biological Cycle of Lutzomyia evandroi Costa Lima \& Antunes, 1936 (Diptera: Psychodidae) under Experimental Conditions. Mem. Inst. Oswaldo Cruz 2001, 96, 883-886. [CrossRef]

56. Hurwitz, I.; Hillesland, H.; Fieck, A.; Das, P.; Durvasula, R. The paratransgenic sand fly: A platform for control of Leishmania transmission. Parasit Vectors 2011, 4, 82. [CrossRef] [PubMed]

57. Peterkova-Koci, K.; Robles-Murguia, M.; Ramalho-Ortigao, M.; Zurek, L. Significance of bacteria in oviposition and larval development of the sand fly Lutzomyia longipalpis. Parasit Vectors 2012, 5, 145. [CrossRef]

58. Hammer, T.J.; Moran, N.A. Links between metamorphosis and symbiosis in holometabolous insects. Philos. Trans. R. Soc. B Biol. Sci. 2019, 374, 20190068. [CrossRef]

59. Schlein, Y.; Muller, G. Assessment of plant tissue feeding by sand flies (Diptera: Psychodidae) and mosquitoes (Diptera: Culicidae). J. Med. Entomol. 1995, 32, 882-887. [CrossRef]

60. Moore, J.S.; Kelly, T.B.; Killick-Kendrick, R.; Killick-Kendrick, M.; Wallbanks, K.R.; Molyneux, D.H. Honeydew sugars in wildcaught Phlebotomus ariasi detected by high performance liquid chromatography (HPLC) and gas chromatography (GC). Med. Vet. Entomol. 1987, 1, 427-434. [CrossRef]

61. Cameron, M.M.; Pessoa, F.A.C.; Vasconcelos, A.W.; Ward, R.D. Sugar meal sources for the phlebotomine sandfly Lutzomyia longipalpis in Ceará State, Brazil. Med. Vet. Entomol. 1995, 9, 263-272. [CrossRef]

62. Wallbanks, K.R.; Moore, J.S.; Bennett, L.R.; Soren, R.; Molyneux, D.H.; Carlin, J.M.; Perez, J.E. Aphid derived sugars in the neotropical sandfly-Lutzomyia peruensis. Trop Med. Parasitol. 1991, 42, 60-62. [PubMed]

63. Tang, Y.; Ward, R.D. Sugar feeding and fluid destination control in the phlebotomine sandfly Lutzomyia longipalpis (Diptera: Psychodidae). Med. Vet. Entomol. 1998, 12, 13-19. [CrossRef]

64. Samakovlis, C.; Kylsten, P.; Kimbrell, D.A.; Engstrom, A.; Hultmark, D. The Andropin gene and its product, a male-specific antibacterial peptide in Drosophila melanogaster. EMBO J. 1991, 10, 163-169. [CrossRef] 
65. Lung, O.; Kuo, L.; Wolfner, M.F. Drosophila males transfer antibacterial proteins from their accessory gland and ejaculatory duct to their mates. J. Insect Physiol. 2001, 47, 617-622. [CrossRef]

66. Ferrandon, D.; Jung, A.C.; Criqui, M.; Lemaitre, B.; Uttenweiler-Joseph, S.; Michaut, L.; Reichhart, J.; Hoffmann, J.A. A drosomycinGFP reporter transgene reveals a local immune response in Drosophila that is not dependent on the Toll pathway. EMBO J. 1998, 17, 1217-1227. [CrossRef]

67. Kelly, P.H.; Bahr, S.M.; Serafim, T.D.; Ajami, N.J.; Petrosino, J.F.; Meneses, C.; Kirby, J.R.; Valenzuela, J.G.; Kamhawi, S.; Wilson, M.E. The Gut Microbiome of the Vector Lutzomyia longipalpis Is Essential for Survival of Leishmania infantum. $m B i o$ 2017, 8, e01121-16. [CrossRef] [PubMed]

68. Shir-Shapira, H.; Sharabany, J.; Filderman, M.; Ideses, D.; Ovadia-Shochat, A.; Mannervik, M.; Juven-Gershon, T. Structurefunction analysis of the Drosophila melanogaster caudal transcription factor provides insights into core promoter-preferential activation. J. Biol. Chem. 2015, 290, 17293-17305. [CrossRef]

69. Ryu, J.H.; Kim, S.H.; Lee, H.Y.; Jin, Y.B.; Nam, Y.; Bae, J.W.; Dong, G.L.; Seung, C.S.; Ha, E.M.; Lee, W.J. Innate immune homeostasis by the homeobox gene Caudal and commensal-gut mutualism in Drosophila. Science 2008, 319, 777-782. [CrossRef]

70. Lainson, R.; Rangel, E.F. Lutzomyia longipalpis and the eco-epidemiology of American visceral leishmaniasis, with particular reference to Brazil: A review. Mem. Inst. Oswaldo. Cruz 2005, 100, 811-827. [CrossRef] [PubMed]

71. Secundino, N.F.; Eger-Mangrich, I.; Braga, E.M.; Santoro, M.M.; Pimenta, P.F. Lutzomyia longipalpis peritrophic matrix: Formation, structure, and chemical composition. J. Med. Entomol. 2005, 42, 928-938. [CrossRef] [PubMed]

72. Freitas, V.C.; Parreiras, K.P.; Duarte, A.P.; Secundino, N.F.; Pimenta, P.F. Development of Leishmania (Leishmania) infantum chagasi in its natural sandfly vector Lutzomyia longipalpis. Am. J.Trop Med. Hyg. 2012, 86, 606-612. [CrossRef] [PubMed]

73. Wilson, R.; Bates, M.D.; Dostalova, A.; Jecna, L.; Dillon, R.J.; Volf, P.; Bates, P.A. Stage-specific adhesion of Leishmania promastigotes to sand fly midguts assessed using an improved comparative binding assay. PLoS Negl. Trop. Dis. 2010, 4. [CrossRef] [PubMed]

74. Mukhopadhyay, J.; Braig, H.R.; Rowton, E.D.; Ghosh, K. Naturally occurring culturable aerobic gut flora of adult Phlebotomus papatasi, vector of Leishmania major in the Old World. PLoS ONE 2012, 7, e35748. [CrossRef] [PubMed]

75. McCarthy, C.B.; Diambra, L.A.; Rivera Pomar, R.V. Metagenomic analysis of taxa associated with Lutzomyia longipalpis, vector of visceral leishmaniasis, using an unbiased high-throughput approach. PLoS Negl. Trop Dis. 2011, 5, e1304. [CrossRef] [PubMed]

76. Sant'Anna, M.R.; Darby, A.C.; Brazil, R.P.; Montoya-Lerma, J.; Dillon, V.M.; Bates, P.A.; Dillon, R.J. Investigation of the bacterial communities associated with females of Lutzomyia sand fly species from South America. PLoS ONE 2012, 7, e42531. [CrossRef] 